\title{
Biogenic Amines in Insect Antennae
}

\author{
Marianna I. Zhukovskaya * and Andrey D. Polyanovsky \\ Laboratory of Evolution of Sense Organs, Sechenov Institute of Evolutionary Biochemistry and Physiology, Russian Academy
} of Sciences, Saint Petersburg, Russia

Insect antenna is a multisensory organ, each modality of which can be modulated by biogenic amines. Octopamine (OA) and its metabolic precursor tyramine (TA) affect activity of antennal olfactory receptor neurons. There is some evidence that dopamine (DA) modulates gustatory neurons. Serotonin can serve as a neurotransmitter in some afferent mechanosensory neurons and both as a neurotransmitter and neurohormone in efferent fibers targeted at the antennal vessel and mechanosensory organs. As a neurohormone, serotonin affects the generation of the transepithelial potential by sensillar accessory cells. Other possible targets of biogenic amines in insect antennae are hygro- and thermosensory neurons and epithelial cells. We suggest that the insect antenna is partially autonomous in the sense that biologically active substances entering its hemolymph may exert their effects and be cleared from this compartment without affecting other body parts.

Keywords: insect, antenna, sensory plasticity, octopamine, tyramine, serotonin, dopamine

\section{INTRODUCTION}

\section{OPEN ACCESS}

Edited by:

Irina T. Sinakevitch, Arizona State University, United States

Reviewed by: Glenn Turner, Janelia Research Campus, United States Hui-Yun Chang,

National Tsing Hua University, Taiwan

${ }^{*}$ Correspondence: Marianna I. Zhukovskaya mzhukovskaya@yahoo.com

Received: 01 March 2017 Accepted: 06 June 2017 Published: 28 June 2017

Citation:

Zhukovskaya MI and Polyanovsky $A D$ (2017) Biogenic Amines in Insect Antennae.

Front. Syst. Neurosci. 11:45. doi: 10.3389/fnsys.2017.00045
Insect antennae are complex sensory appendages engaged in acquiring information from different mechanical, gustatory and olfactory as well as thermal and humidity cues (Altner et al., 1977). The antenna consists of two basal segments having muscles, which control antennal movements, and flagellum devoid of muscles but bearing sensilla, miniature sensory organs. The antenna is supplied by oxygen through the trachea, originating from the spiracles which are positioned laterally in the thoracic and abdominal segments (Newport, 1836; Yadav, 2003). Haemolymph flows through the antennal vessel pumped by the antennal heart, a circulatory organ found in a handful of insect species (Pass, 2000; Pass et al., 2006). The proximal part of the antennal vessel shows features of the ion-transporting function (Pawlowa, 1895). Hemolymph spills from the vessel into the antennal hemolymphatic space through the openings in the vessel walls, called ostia, and the distal pore (Kapitskii, 1984; Pass et al., 2006; Boppana and Hillyer, 2014). Hormones and other biologically active substances are delivered to the antennal lumen from the two main sources-body hemolymph and secretion from nerve terminals in the wall of the antennal heart (Beattie, 1976; Figure 1). No centrifugal axonal processes were found in the antennal flagella other than those coming from tachykinin-reactive cells in the mosquito Culex salinarius, which form axo-dendritic synapses with sensory neurons (Meola and Sittertz-Bhatkar, 2002). The neurohemal area in the antennal heart ampulla of the cockroach Periplaneta americana releases octopamine (OA) into the antennal hemolymph under control of dorsal unpaired median (DUM) neurons, originating from the suboesophageal ganglion (Pass et al., 1988). The possible targets for OA are: (1) sensory receptor organs-sensilla, tuned to olfactory, gustatory and various mechanical cues as well as to humidity and temperature; and (2) non-sensory tissues including the ion-transporting epithelium in the antennal vessel (Pass, 1985) and hypoderm (Figure 2). Considerable length of antennae suggests the possibility of mainly local humoral modulation, since active substances contained in 
the hemolymph have enough time to exert their effect and be cleared out before returning to the head and body hemocoel (Figure 1).

The tremendous ability of insects to prosper owes, in part, their behavioral plasticity in response to environmental cues. Perception of pheromones and non-pheromone odors by an insect changes depending on various factors, such as age (Takasu and Lewis, 1996; Mechaber et al., 2002; Bohbot et al., 2013), physiological state (Blaney et al., 1986; Anton et al., 2007; Evenden and Gries, 2008), previous experience (Anton et al., 2011; Minoli et al., 2012; Riffell and Hildebrand, 2016), sensory surrounding (Yang et al., 2004; Zhao et al., 2013; Deisig et al., 2014) and circadian rhythmicity (Linn and Roelofs, 1986; Saifullah and Page, 2009; Schendzielorz et al., 2012).

During a long time, plasticity of behavioral responses was attributed to neuromodulation in the central nervous system rather than in antennal sensillae (Roelofs, 1995). However, after the study by von Nickisch-Rosenegk et al. (1996), showing the presence of biogenic amine receptors in the moth antenna, it is accepted now that all levels, from sensory input to motor output, involved in the organization of olfactionguided behavior are under neurohumoral control (Anton et al., 2007).

All receptors of biogenic amines revealed in insects thus far represent membrane-bound $G$ protein-coupled receptors
(GPCRs), triggering different signaling cascades, which lead to a rise or fall in the cAMP level and $\mathrm{Ca}^{2+}$ release (Blenau and Baumann, 2001; Beggs et al., 2011; Ohta and Ozoe, 2014; Vleugels et al., 2015). The cross-talk between their signaling pathways and the intracellular biochemical machinery in antennal tissues is attracting attention of researchers (Flecke and Stengl, 2009; Flecke et al., 2010; Chen and Luetje, 2014), but is not studied in detail.

This review addresses those peripheral effects of biogenic amines-OA, tyramine (TA), serotonin (5-HT), and dopamine (DA) - that are confined to the antenna, the major sensory organ in insects.

\section{OCTOPAMINE}

\section{Olfactory Reception}

OA, topically applied or injected into an insect body, evokes pronounced changes in olfactory responses, both behavioral (Linn and Roelofs, 1986; Linn et al., 1992; Zhukovskaya, 2008) and electrophysiological (Pophof, 2000, 2002; Grosmaitre et al., 2001; Kapitsky and Zhukovskaya, 2001; Zhukovskaya and Kapitsky, 2006; Flecke and Stengl, 2009; Zhukovskaya, 2012). Besides, OA increases the spontaneous activity of pheromone-sensitive olfactory receptor neurons (ORNs) in some insect preparations (Grosmaitre et al., 2001; Zhukovskaya and Kapitsky, 2006; Flecke and Stengl, 2009;

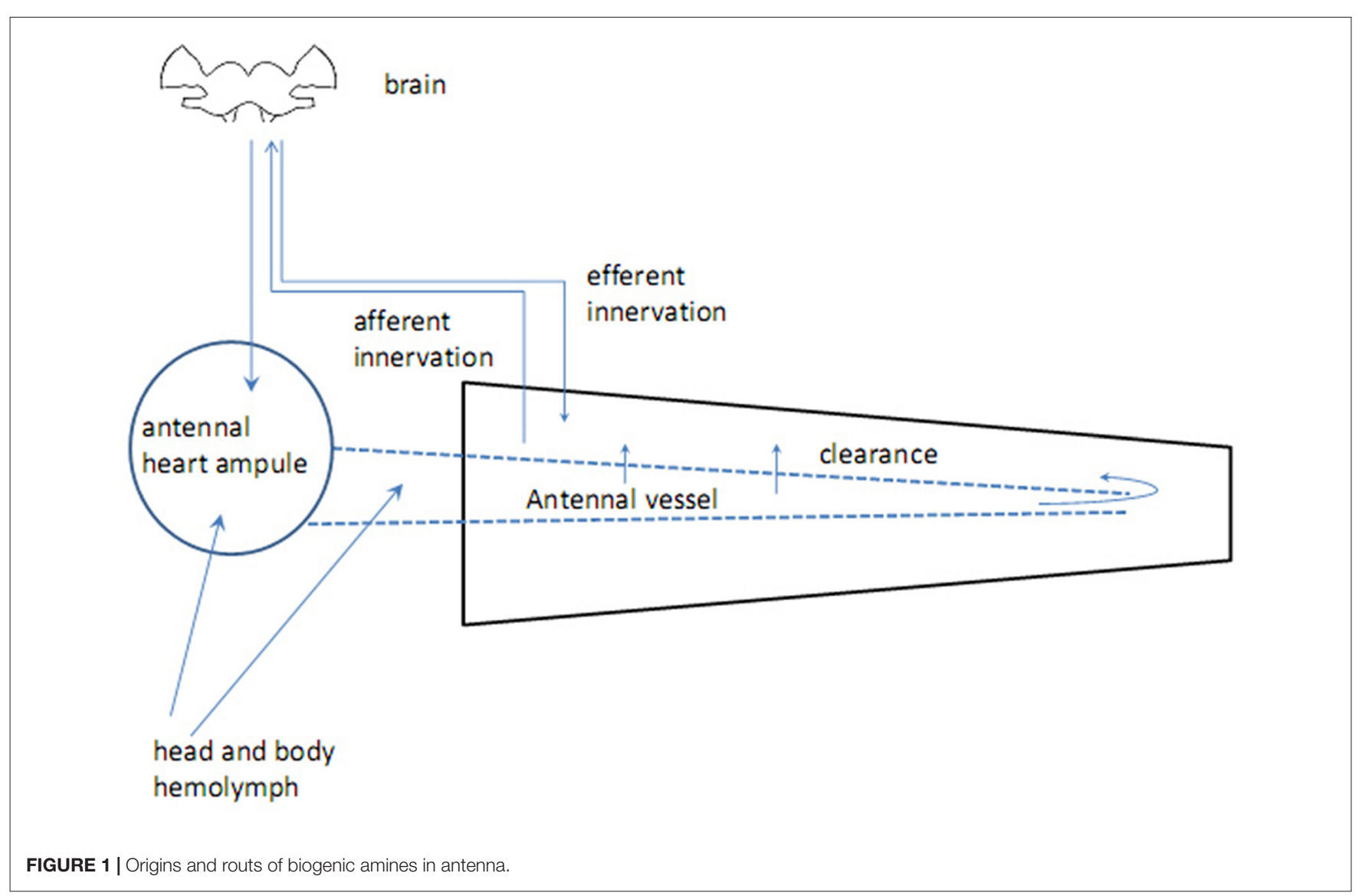




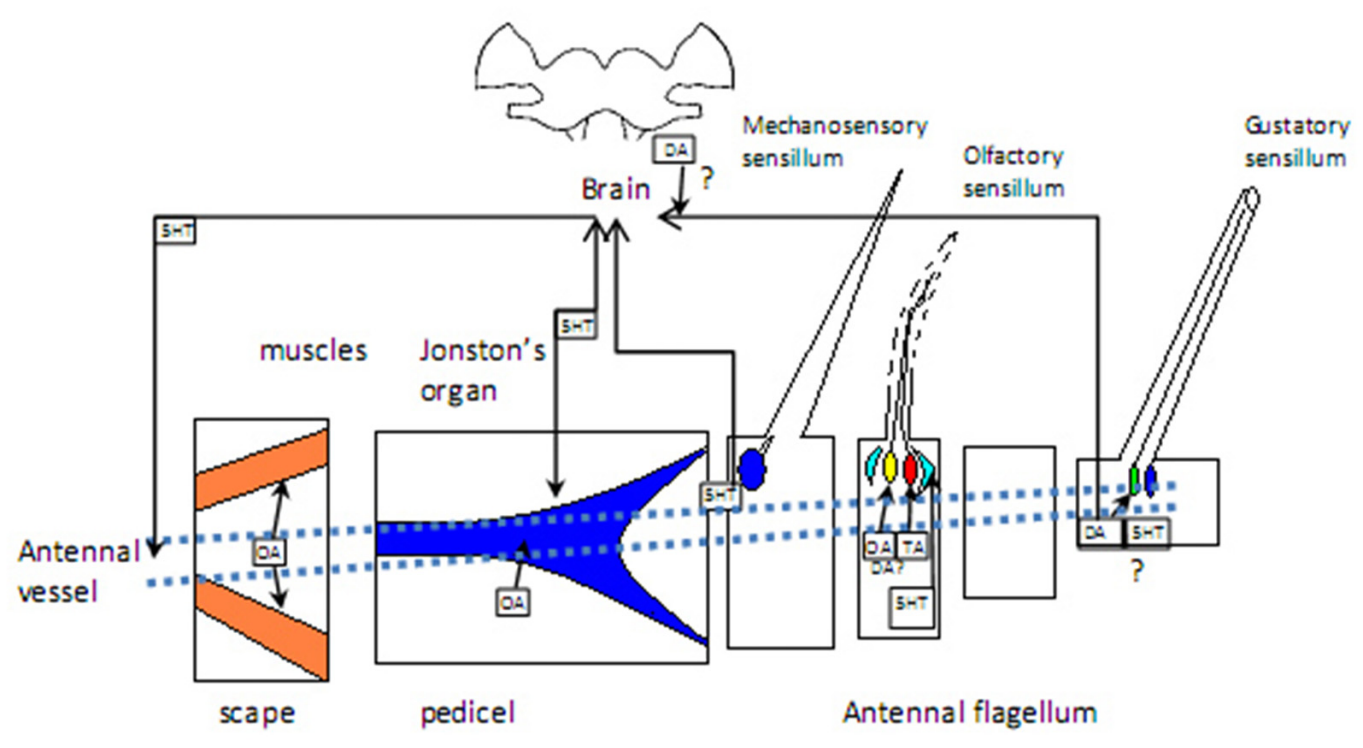

$\rightarrow \quad$ Centrifugal influences

$\rightarrow \quad$ Centripetal influences

FIGURE 2 | Targets of aminergic regulation: sensilla of different modality, muscles in basal segments, antennal vessels. Sources of biogenic amines: sensory neurons. Question marks denote unresolved issues. Blue: mechanosensory structures; green: gustatory cells; yellow and red: olfactory cells responding to different odors; light blue: accessory cells; orange: muscles. See the text for more information.

Stengl, 2010). In general, OA enhances behavioral responses to attractants (Linn and Roelofs, 1986; Zhukovskaya, 2008; $\mathrm{Ma}$ et al., 2015), improves nestmate recognition in ants (Vander Meer et al., 2008), and sometimes changes the valence of an odor, making neutral odor attractive and repellent odor neutral, as shown previously (Zhukovskaya, 2012).

Although these data shed some light on the role of octopaminergic regulation in insect olfaction, two issues were left unresolved. First, endogenous OA release can be induced by experimental manipulatons. For example, handling alone evokes a 3 -fold rise in the OA level in the $P$. americana antennal heart, which supplies the antenna with hemolymph (Möbius and Penzlin, 1993). Besides, injections of agonists as well as antagonists of OA and TA induce a similar rise in displacement grooming suggested to be a dearousing behavior due to stress-induced changes in the OA level (Fussnecker et al., 2006). Second, response modulation, usually attributed to a direct effect of OA, may result from the indirect effect of other biologically active molecules released by OA. Outside the antennae, OA significantly changes the production of juvenile hormone and 20-hydroxyecdysone in cockroaches and flies (Downer et al., 1984; Gruntenko et al., 2007) and adipokinetic hormone in crickets (Orchard et al., 1983), which affect multiple targets throughout the insect body.

Upregulation of single cell olfactory responses coincides with an OA-induced decrease in the electroantennogram (EAG) amplitude. However, it is noteworthy that changes in EAG under the influence of $\mathrm{OA}$ and other humoral factors should be interpreted with caution, since EAG is a complex signal rather than just a voltage drop caused by arithmetical summation of leak currents from ORNs. EAG strongly depends on the electrical resistance of the antennal tissue as well as on the position of recording electrodes relative to the responding sensilla (Nagai, 1981; White, 1991; Kapitskii and Gribakin, 1992). Data reported by Dolzer et al. (2001) showed a dose-dependent decrease in the resistance of the sensillum preparation in the moth Manduca sexta under the impact of OA. The simultaneous OA-induced decrease in the EAG amplitude and increase in the action potential frequency led us to suggest that OA causes a depolarization in the ORN resting potential (Kapitsky and Zhukovskaya, 2001). As a result, the reduced ORN membrane potential requires smaller changes to reach the threshold potential level, at which action potentials are triggered, creating smaller currents recorded as EAG after the summation of these miniature leaks from responding ORNs along the antennal length. At the same time, the depolarized membrane is less stable, 
triggering more spikes in response to the odor stimulus. Recently, this concept has gained further support (Flecke and Stengl, 2009; Stengl, 2010).

Taking the advantage of the fact that the antennal flagellum is devoid of OA-producing structures, we performed single sensillum recording from the preparations of the isolated cockroach antennal flagellum (Kapitsky and Zhukovskaya, 2001; Zhukovskaya and Kapitsky, 2006) perfused with OA and OA-free saline. This approach allowed us both to administer and wash out $\mathrm{OA}$ as well as to control other hemolymp-born substances that bathe proximal parts of ORNs. The increase in the spiking rate in sex-specific male cockroach sensilla in response to pheromone and its background activity proved unequivocally that response modulation in the pheromonesensitive ORNs results from the direct effect of OA. This finding was later supported in the other cockroach species, Rhyparobia (Leucophaea) maderae (Schendzielorz et al., 2012), using perfused sensillum preparations. OA-dependent local release of tachykinin inside the sensillum, as suggested by Jung et al. (2013), provides further downstream regulation of cells in the olfactory sensilla, possibly affecting EAG responses to odors.

Peripheral responses to general odorants may or may not be under OA control (Pophof, 2002; Zhukovskaya, 2012). Our data suggest that some of the hexanol-1-sensitive sensilla, morphologically and physiologically differing from the sex-pheromone sensitive ones (Schaller, 1978; Fujimura et al., 1991), are under OA control in adult $P$. americana males, while other sensilla are not affected (Zhukovskaya, 2012). To ascertain if the olfactory sensillum is modulated by OA via its effect on accessory cells, which partially create a driving force for the receptor current in response to odorants (Kaissling, 1987) and control the composition of the sensillum lymph (Thurm and Küppers, 1980; Keil, 1999), or each ORN is affected independently, we took the advantage of the fact that $P$. americana pheromone-sensitive sensilla houses both pheromone-sensitive and general odorant-sensitive "eucalyptol" cells. OA application enhanced firing responses of this type of sensilla to both pheromone components, periplanones A and $\mathrm{B}$, but did not affect responses to eucalyptol (Zhukovskaya and Kapitsky, 2006; Zhukovskaya, 2012). Thus, in contrast to the cells responding to pheromone components and controlled by $\mathrm{OA}$, the cell responding to general odorant is not OA-controlled. These data provide evidence that receptor cells inside the same sensillum, at least in some cases, are controlled independently via biogenic amine receptors on the ORN membrane. It is important to note that all the tested odorants, namely, pheromone components and plant-derived odorants, eucalyptol and hexanol, showed a decrease in EAG under the effect of OA. We did not detect significant changes in firing responses to eucalyptol, but cannot rule out that other receptor cells in other types of sensilla respond to this odor differently in the presence or absence of OA. Another possible explanation of the uniform EAG decrease under the effect of $\mathrm{OA}$ in response to all tested odors is a change in the electrical resistance of non-sensory antennal tissues, such as hemolymph, epithelium or cuticle, which contributes to the cumulative resistance of the antennal preparation. It appears that OA release into antennal hemolymph switches the mode of its functioning, altering the antennal sensitivity to a particular set of pheromone components and environmental odors in order to better conform the specific needs of the animal.

Coupling of olfactory sensitivity modulation by OA with circadian rythmicity was initially found in the cabbage looper moth Trichoplusia ni (Linn and Roelofs, 1986; Linn et al., 1992). Later, OA modulation of olfactory sensitivity in the antenna of $M$. sexta was found to be linked to the circadian rhythmicity in pheromone reception through cAMP-dependent disadaptation in receptor cells (Flecke and Stengl, 2009; Flecke et al., 2010; Stengl, 2010). The antennal OA receptor cloned in the $M$. sexta shares high sequence similarity with other insect $\alpha$-adrenergic-like OA receptors and increases both cAMP and $\mathrm{Ca}^{2+}$ intracellular concentration in response to an agonist (Dacks et al., 2006). $\mathrm{Ca}^{2+}$ and cAMP levels altered due to OA-induced signal transduction are supposed to act through metabotropic activation of Orco, an odorant receptor coreceptor protein, leading to changes in ORN sensitivity (Getahun et al., 2013; Stengl and Funk, 2013).

Octopaminergic modulation in the antenna can be enhanced not only by the elevation of the OA level, but also by upregulation of OA receptors in the antenna of honey bee workers, as shown using the Real-time qPCR technique (McQuillan et al., 2012). Thus, expression of OA receptors (AmOA1) in the antenna was found to be higher in young nurses as compared to pollen foragers of the same age, corresponding to sensitivity to queen mandibular pheromone (QMP). Foragers in the bee colony are not attracted by QMP while the expression level of antennal AmOA1 is low (Vergoz et al., 2009). AmOA1 also belongs to the $\alpha$-adrenegic-like OA receptor family that induces an oscillatory increase in the intracellular $\mathrm{Ca}^{2+}$ concentration under OA stimulation but only a slight elevation of the cAMP level (Grohmann et al., 2003).

\section{Other Targets of Octopamine in Insect Antenna}

Muscles situated in the first two antennal segments, scape and pedicel (Chapman, 1998), control movements of the flagellum through motoneurons and modulating neurons, including octopaminergic DUM neurons, descending from the suboesophageal ganglion (Bräunig et al., 1990; Bauer and Gewecke, 1991; Baba and Comer, 2008; Figure 2). Stimulation of these cells as well as OA application attenuates slow and enhances fast contractions in cricket preparations (Allgäuer and Honegger, 1993), facilitating fast antennal movements during tracking a target.

The mechanosensory Johnston's organ, responding to vibrations and low frequency sounds, was recently found to be modulated by OA, which shifts frequency tuning and is likely to allow mosquito males to track females by following their changing flight sound tones due to movement (Andrés et al., 2016). Interestingly, despite the fact that OA plays an important role in arousal and aggression, the threshold for mechanical stimulation of antennae, causing an aggressive response in male crickets, does not depend on OA (Rillich and Stevenson, 2015; Stevenson and Rillich, 2016). Thus, central rather than peripheral 
mechanosensory octopaminergic modulation is responsible for adjusting the level of aggression in response to stimulation of antennal mechanosensitive sensilla.

\section{TYRAMINE}

TA is, on the one hand, an OA biosynthetic precursor, but on the other hand, it plays a distinctive role in an insect body. Since there were identified some TA-containing neurons devoid of $\mathrm{OA}$, the specific role of TA as a neuroactive compound became evident (Nagaya et al., 2002). In fact, TA and OA are believed to be, in a sense, functionally antagonistic (Roeder et al., 2003; Roeder, 2005; Lange, 2009). For example, in contrast to attractive (pheromone) odors modulated by OA, behavioral responses to aversive (non-pheromone) odors are affected by TA because they were decreased in hono, the Drosophila melanogaster TA (TA/OA) receptor knockout (Kutsukake et al., 2000). However, it is preliminary to conclude that OA modulates pheromonesensitive ORNs while TA affects general odorant-sensitive ORNs, because our above data on OA-upregulated responses to the non-pheromone repellent odor of hexanol (Zhukovskaya, 2008, 2012) indicate that responses to general odorants can be regulated by OA. It is also unlikely that there is a strict division of functions, when TA modulates responses to repellents whereas OA modulates attractants, because the valence of a particular odor can be changed by learning and other experiencebased effects (McCall and Eaton, 2001; Saleh and Chittka, 2006; Anderson and Anton, 2014). X-gal staining of the hono gene product revealed about 10 most probable ORN candidates in the third antennal segment, the main olfactory organ in an adult fly, as well as in the larval dorsal olfactory organ. Although first lepidopteran OAR/TAR, identified in B. mori and H. virescens, were thought to be OAR (von Nickisch-Rosenegk et al., 1996), it has been demonstrated later that at least in B. mori OAR/TAR is two orders of magnitude more sensitive to TA than to OA and shows much higher affinity (by about 270 times) to TA than $\mathrm{OA}$, representing, in fact, a TA receptor. TA activation of this receptor leads to $\mathrm{G}_{i}$ protein-mediated inactivation of adenylate cyclase and a reduction in intracellular cAMP levels (Ohta et al., 2003, 2004).

In honey bee antennae, downregulation of OA receptors Amoal and upregulation of TA receptors AmTAR1 were revealed during transition from QMP-sensitive nurses to plant odor-sensitive foragers as detected by a real-time quantitative PCR technique (McQuillan et al., 2012). Another TA receptor from the honey bee, AmTAR2, was shown to increase the intracellular cAMP level in the flpTM heterologous expression system (Reim et al., 2017), but so far is not found in insect antennae.

In the adult $M$. brassicae, TA receptor (MbraOAR/TAR) transcripts were detected both in pheromone- and general odor-sensitive antennal sensilla (Brigaud et al., 2009). TA not only affects ORNs in insect antennae, but itself can be synthesized by some of them (Figures 1, 2). Presumably, in the blowfly Phormia regina it acts in the antennal lobe neuropile through modulation of responses to aversive odor of d-limonene (Ishida and Ozaki, 2012). Since TA receptors mostly decrease while
OA receptors increase the cAMP level (Ohta and Ozoe, 2014), their effects on cAMP-dependent intracellular events should be mutually opposite, but whether these receptors co-localize in the same cell is an open question.

Tryptamine, produced in plants as their defense reaction against insect herbivores, was found to be antagonistic to olfactory co-receptor Orco in the low micromolar range (Chen and Luetje, 2014), probably interacting with TA or OA binding sites.

\section{SEROTONIN}

It is generally accepted that in insect antennal ORNs, the role of neurotransmitter is played by acetylcholine, although there are a few pieces of evidence deviating from this tenet. Serotoninimmunoreactive fibers were identified in the antennal nerve of P. americana (Salecker and Distler, 1990), projecting into antennal mechanosensory and contact chemosensory centers mainly in the deutocerebrum. Later, cell bodies of these sensory neurons were found in mechanosensory chaetic and scolopoidial sensilla in the scape, pedicel and first 15 flagellomeres. Moreover, efferent fibers were found within the scape, ramifying along the antennal vessel and inner margin of the epidermal layer without contacting them synaptically (Watanabe et al., 2014). Serotoninergic efferent fibers have also been identified in mosquitoe antennae, where they are targeted at the antennal flagellum and scolopidia of the Johnston's organ (Siju et al., 2008; Andrés et al., 2016). Transcriptomic analysis revealed few putative 5-HT receptor proteins in the antennae of the mosquito Anopheles gambiae (Pitts et al., 2011), supporting the role of 5-HT as a neurohormone. 5-HT affects the transepithelial potential, generated by accessory cells in the olfactory sensillum and creating a driving force for the receptor current (Dolzer et al., 2001; Grosmaitre et al., 2001).

The direct effect of 5-HT on firing responses in the blowfly Phormia regina labellar gustatory receptor neurons during the specific stage of their ovarian maturation period indicates a peripheral modulation of gustatory receptor neurons. Exogenous 5-HT supply specifically increases the chemoreceptor sensitivity to sugar at the mature ovaries and post egg-laying stages (Solari et al., 2015). However, it is not clear whether antennal gustatory neurons are serotonin-modulated or the effect of 5-HT is labellum-specific and this issue should be a matter of future research (Figure 2).

\section{DOPAMINE}

\section{Olfactory Reception}

There are indications that DA can serve as a neurohormone, modulating odor responses. Expression of the DA receptor Amdop3 in the honey bee antenna was found to correlate with an age-dependent decrease in sensitivity of honey bee workers to the QMP component (Vergoz et al., 2009; McQuillan et al., 2012). The age-dependent decrease in pheromone sensitivity in the male black cutworm Agrotis ipsilon is also thought to be associated with DA signaling via the G protein-coupled DA/ecdysteroid receptor AipsDopEc, however, this effect is attributed to the brain 
level, since antennal expression was low and age-independent (Abrieux et al., 2013).

\section{Gustatory Reception}

Most data on gustatory reception were obtained on flies, which bear short antennae unable to touch the substrate to perform gustatory function, whereas flies taste food using sensilla located on the labella. Gustatory plasticity, similarly to above-described olfactory plasticity, is achieved at different levels of sensory processing. Starvation (nutritional stress) causes changes in the sugar-sensitive gustatory receptor on the fly labellar sensilla due to increased expression of the Gr64a receptor gene (Nishimura et al., 2012). Since responses to nutritional stress in flies are accompanied by changes in biogenic amine levels (Gruntenko et al., 2005), it was logical to look for dopaminergic regulation in gustatory receptor neurons. DA receptors were found to enhance sucrose sensitivity under starvation in Drosophila sucrose-sensitive gustatory receptor cells (Inagaki et al., 2012). At the same time, bitter sensitive neurons decrease their output during OA and TA modulation (Inagaki et al., 2014; LeDue et al., 2016). In both cases, however, modulation occurs presynaptically on axonal terminals, projecting from the fly labellum to primary gustatory neuropile of the suboesophageal ganglion.

A majority of insects other than flies bear gustatory sensilla on antennae and are likely to use similar dopaminergic regulatory mechanisms. For example, unpaired H-cells with their bodies located in the suboesophageal ganglion of moths and orthopterans (Mesce et al., 2001) release DA that can be transported to antennae (Galizia and Rössler, 2010).

DA receptors were demonstrated to be expressed in honey bee antennae; moreover, changes in the expression level of one of them, Amdop1, corresponded to the transition from nursing to foraging (McQuillan et al., 2012). Since QMP contains some non-volatile components, DA appears to be a plausible modulator candidate in pheromone-sensing gustatory receptor neurons (Figure 2).

\section{Other Possible Targets of Aminergic Modulation in Antenna}

The outer layer of the cuticle bears waxes or liquid cuticular hydrocarbons, the repertoire of which may be body part specific (Oppelt and Heinze, 2009; Bagnères and Blomquist, 2010). Our data suggest that the liquid coating of the cockroach antenna plays an important role in olfaction (Böröczky et al., 2013), providing, in concert with grooming, odorant cleanout from the antennal surface. It can be hypothesized that the cuticular lipid secretion is modulated via the neurohumoral (probably, aminergic) mechanism. Thermosensory neurons may

\section{REFERENCES}

Abrieux, A., Debernard, S., Maria, A., Gaertner, C., Anton, S., Gadenne, C., et al. (2013). Involvement of the G-protein-coupled dopamine/ecdysteroid receptor DopEcR in the behavioral response to sex pheromone in an insect. PLoS One 8:e72785. doi: 10.1371/journal.pone.0072785 also be modulated by the hemolymph-born molecules. No direct measurements of thermosensory neuronal responses in the presence of biogenic amines have been found in literature, but some clues on the possibility of the modulation can be found. For example, in the blood-feeding yellow fever mosquito Aedes aegypti, long-range perception of $\mathrm{CO}_{2}$ changes behavioral responses to a short-range thermal signal (McMeniman et al., 2014). The satiety level, interrelated with the 5-HT titer (Lange et al., 1989), influences the response to heat in the bug Rhodnius prolixus (Bodin et al., 2009). Previous experience changes behavioral responses to thermal stimulation in the worker ant Camponotus rufipes (Weidenmüller et al., 2009) and bumblebee Bombus terrestris (Westhus et al., 2013) in a way similar to that described for olfactory reception.

\section{CONCLUSIONS}

The insect antenna is a multisensory organ, and each modality can be modulated by biogenic amines. It appears that insect antenna is partially autonomous in the sense that biologically active substances entering its hemolymph may exert their specific effects and be removed predominantly or even totally inside this compartment without affecting other body parts. OA increases activity of pheromone- and some, but not all, non-pheromone-sensitive antennal ORNs. There is some evidence that DA modulates gustatory receptor neurons. TA, a metabolic OA precursor, also modulates ORNs, usually in an antagonistic manner to $\mathrm{OA}$, but it is unclear if TA and OA receptors are co-localized in receptor neurons. Serotonin can serve as a neurotransmitter in some afferent mechanosensory neurons and both as a neurotransmitter and neurohormone in efferent fibers targeted at the antennal vessel and mechanosensory organs. Aminergic modulation of thermoand hygrosensory sensilla has not yet been demonstrated, and could potentially be another target for modulation. Functioning of non-sensory antennal tissues in the epithelium, tracheae and hemolympatic vessel may also be under humoral control, including aminergic.

\section{AUTHOR CONTRIBUTIONS}

MIZ, ADP: manuscript planning, MIZ: draft writing, ADP: editing.

\section{FUNDING}

Salaries to MIZ and ADP during the work on the manuscript were paid by the State budget of Russian Federation fund for 2013-2017 years (No 01201351571).

Allgäuer, C., and Honegger, H. W. (1993). The antennal motor system of crickets: modulation of muscle contractions by a common inhibitor, DUM neurons, and proctolin. J. Comp. Physiol. A 173, 485-494. doi: 10.1007/bf0 0193521

Altner, H., Sass, H., and Altner, I. (1977). Relationship between structure and function of antennal chemoreceptive, hygroreceptive, and thermoreceptive 
sensilla in Periplaneta americana. Cell Tissue Res. 176, 389-405. doi: $10.1007 /$ bf00221796

Anderson, P., and Anton, S. (2014). Experience-based modulation of behavioural responses to plant volatiles and other sensory cues in insect herbivores. Plant Cell Environ. 37, 1826-1835. doi: 10.1111/pce. 12342

Andrés, M., Seifert, M., Spalthoff, C., Warren, B., Weiss, L., Giraldo, D., et al. (2016). Auditory efferent system modulates mosquito hearing. Curr. Biol. 26, 2028-2036. doi: 10.1016/j.cub.2016.05.077

Anton, S., Dufour, M. C., and Gadenne, C. (2007). Plasticity of olfactoredguided behaviour and its neurobiological basis: lessons from moths and locusts. Entomol. Exp. Appl. 123, 1-11. doi: 10.1111/j.1570-7458.2007.00516.x

Anton, S., Evengaard, K., Barrozo, R. B., Anderson, P., and Skals, N. (2011). Brief predator sound exposure elicits behavioral and neuronal long-term sensitization in the olfactory system of an insect. Proc. Natl. Acad. Sci. U S A 108, 3401-3405. doi: 10.1073/pnas.1008840108

Baba, Y., and Comer, C. M. (2008). Antennal motor system of the cockroach, Periplaneta americana. Cell Tissue Res. 331, 751-762. doi: 10.1007/s00441-0070545-9

Bagnères, A.-G., and Blomquist, G. J. (2010). "Site of synthesis, mechanism of transport and selective deposition of hydrocarbons," in Insect Hydrocarbons: Biology, Biochemistry, and Chemical Ecology, eds G. J. Blomquist and A.-G. Bagnères (Cambridge, MA: Cambridge University Press), 75-99.

Bauer, C. K., and Gewecke, M. (1991). Motoneuronal control of antennal muscles in Locusta migratoria. J. Insect Physiol. 37, 551-562. doi: 10.1016/00221910(91)90032-u

Beattie, T. M. (1976). Autolysis in axon terminals of a new neurohaemal organ in the cockroach Periplaneta americana. Tissue Cell 8, 305-310. doi: 10.1016/0040-8166(76)90054-9

Beggs, K. T., Tyndall, J. D. A., and Mercer, A. R. (2011). Honey bee dopamine and octopamine receptors linked to intracellular calcium signaling have a close phylogenetic and pharmacological relationship. PLoS One 6:e26809. doi: 10.1371 /journal.pone.0026809

Blaney, W. M., Schoonhoven, L. M., and Simmonds, M. S. J. (1986). Sensitivity variations in insect chemoreceptors; a review. Experientia 42, 13-19. doi: $10.1007 /$ bf01975876

Blenau, W., and Baumann, A. (2001). Molecular and pharmacological properties of insect biogenic amine receptors: lessons from Drosophila melanogaster and Apis mellifera. Arch. Insect Biochem. Physiol. 48, 13-38. doi: 10.1002/ arch. 1055

Bodin, A., Vinauger, C., and Lazzari, C. R. (2009). Behavioural and physiological state dependency of host seeking in the blood-sucking insect Rhodnius prolixus. J. Exp. Biol. 212, 2386-2393. doi: 10.1242/jeb.030668

Bohbot, J. D., Durand, N. F., Vinyard, B. T., and Dickens, J. C. (2013). Functional development of the octenol response in Aedes aegypti. Front. Physiol. 4:39. doi: 10.3389/fphys.2013.00039

Boppana, S., and Hillyer, J. F. (2014). Hemolymph circulation in insect sensory appendages: functional mechanics of antennal accessory pulsatile organs (auxiliary hearts) in the mosquito Anopheles gambiae. J. Exp. Biol. 217, 3006-3014. doi: 10.1242/jeb.106708

Böröczky, K., Wada-Katsumata, A., Batchelor, D., Zhukovskaya, M., and Schal, C. (2013). Insects groom their antennae to enhance olfactory acuity. Proc. Natl. Acad. Sci. U S A 110, 3615-3620. doi: 10.1073/pnas.1212466110

Bräunig, P., Allgäuer, C., and Honegger, H. W. (1990). Suboesophageal DUM neurones are part of the antennal motor system of locusts and crickets. Experientia 46, 259-261. doi: 10.1007/bf01951758

Brigaud, I., Grosmaître, X., François, M. C., and Jacquin-Joly, E. (2009). Cloning and expression pattern of a putative octopamine/tyramine receptor in antennae of the noctuid moth Mamestra brassicae. Cell Tissue Res. 335, 455-463. doi: $10.1007 / \mathrm{s} 00441-008-0722-5$

Chapman, R. F. (1998). The Insects: Structure and Function. Cambridge, MA: Cambridge University press.

Chen, S., and Luetje, C. W. (2014). Trace amines inhibit insect odorant receptor function through antagonism of the co-receptor subunit. F1000Res. 3:84. doi: 10.12688/f1000research.3825.1

Dacks, A. M., Dacks, J. B., Christensen, T. A., and Nighorn, A. J. (2006). The cloning of one putative octopamine receptor and two putative serotonin receptors from the tobacco hawkmoth, Manduca sexta. Insect Biochem. Mol. Biol. 36, 741-747. doi: 10.1016/j.ibmb.2006.07.002
Deisig, N., Dupuy, F., Anton, S., and Renou, M. (2014). Responses to pheromones in a complex odor world: sensory processing and behavior. Insects 5, 399-422. doi: 10.3390/insects5020399

Dolzer, J., Krannich, S., Fischer, K., and Stengl, M. (2001). Oscillations of the transepithelial potential of moth olfactory sensilla are influenced by octopamine and serotonin. J. Exp. Biol. 204, 2781-2794.

Downer, R. G. H., Orr, G. L., Gole, J. W. D., and Orchard, I. (1984). The role of octopamine and cyclic AMP in regulating hormone release from corpora cardiaca of the American cockroach. J. Insect Physiol. 30, 457-462.doi: 10.1016/0022-1910(84)90025-8

Evenden, M. L., and Gries, R. (2008). Plasticity of male response to sex pheromone depends on physiological state in a long-lived moth. Anim. Behav. 75, 663-672. doi: 10.1016/j.anbehav.2007.07.020

Flecke, C., Nolte, A., and Stengl, M. (2010). Perfusion with cAMP analog affects pheromone-sensitive trichoid sensilla of the hawkmoth Manduca sexta in a time-dependent manner. J. Exp. Biol. 213, 842-852. doi: 10.1242/jeb.032839

Flecke, C., and Stengl, M. (2009). Octopamine and tyramine sensitize pheromonesensitive olfactory sensilla of the hawkmoth Manduca sexta in a daytimedependent manner. J. Comp. Physiol. A Neuroethol. Sens. Neural Behav. Physiol. 195, 529-545. doi: 10.1007/s00359-009-0429-4

Fujimura, K., Yokohari, F., and Tateda, H. (1991). Classification of antennal olfactory receptors of the cockroach, Periplaneta americana L. Zool. Sci. 8, $243-255$.

Fussnecker, B. L., Smith, B. H., and Mustard, J. A. (2006). Octopamine and tyramine influence the behavioral profile of locomotor activity in the honey bee (Apis mellifera). J. Insect Physiol. 52, 1083-1092. doi: 10.1016/j.jinsphys. 2006.07.008

Galizia, C. G., and Rössler, W. (2010). Parallel olfactory systems in insects: anatomy and function. Annu. Rev. Entomol. 55, 399-420. doi: 10.1146/annurev-ento-112408-085442

Getahun, M. N., Olsson, S. B., Lavista-Llanos, S., Hansson, B. S., and Wicher, D. (2013). Insect odorant response sensitivity is tuned by metabotropically autoregulated olfactory receptors. PLoS One 8:e58889. doi: 10.1371/journal. pone. 0058889

Grohmann, L., Blenau, W., Erber, J., Ebert, P. R., Strünker, T., and Baumann, A. (2003). Molecular and functional characterization of an octopamine receptor from honeybee (Apis mellifera) brain. J. Neurochem. 86, 725-735. doi: 10.1046/j.1471-4159.2003.01876.x

Grosmaitre, X., Marion-Poll, F., and Renou, M. (2001). Biogenic amines modulate olfactory neurons firing activity in Mamestra brassicae. Chem. Senses 26, 653-661. doi: 10.1093/chemse/26.6.653

Gruntenko, N. E., Karpova, E. K., Alekseev, A. A., Chentsova, N. A., Bogomolova, E. V., Bownes, M., et al. (2007). Effects of octopamine on reproduction, juvenile hormone metabolism, dopamine, and 20-hydroxyecdysone contents in Drosophila. Arch. Insect Biochem. Physiol. 65 85-94. doi: 10.1002/arch.20187

Gruntenko, N. E., Karpova, E. K., Adonyeva, N. V., Chentsova, N. A., Faddeeva, N. V., Alekseev, A. A., et al. (2005). Juvenile hormone, 20-hydroxyecdysone and dopamine interaction in Drosophila virilis reproduction under normal and nutritional stress conditions. J. Insect Physiol. 51, 417-425. doi: 10.1016/j.jinsphys.2005.01.007

Inagaki, H. K., Ben-Tabou de-Leon, S., Wong, A. M., Jagadish, S., Ishimoto, H., Barnea, G., et al. (2012). Visualizing neuromodulation in vivo: TANGOmapping of dopamine signaling reveals appetite control of sugar sensing. Cell 148, 583-595. doi: 10.1016/j.cell.2011.12.022

Inagaki, H. K., Panse, K. M., and Anderson, D. J. (2014). Independent, reciprocal neuromodulatory control of sweet and bitter taste sensitivity during starvation in Drosophila. Neuron 84, 806-820. doi: 10.1016/j.neuron.2014.09.032

Ishida, Y., and Ozaki, M. (2012). Aversive odorant causing appetite decrease downregulates tyrosine decarboxylase gene expression in the olfactory receptor neuron of the blowfly, Phormia regina. Naturwissenschaften 99, 71-75. doi: 10.1007/s00114-011-0865-1

Jung, J. W., Kim, J. H., Pfeiffer, R., Ahn, Y-J., Page, T. L., and Kwon, H. W. (2013). Neuromodulation of olfactory sensitivity in the peripheral olfactory organs of the American cockroach, Periplaneta americana. PLoS One 8:e81361. doi: 10.1371/journal.pone.0081361

Kaissling, K.-E. (1987). R.H. Wright Lectures on Insect Olfaction. Burnaby, BC: Simon Fraser University. 
Kapitskii, S. V. (1984). Morphology of the antenna of the male American cockroach Periplaneta americana. Zh. Evol. Biokhim. Fizio. 20, 79-86.

Kapitskii, S. V., and Gribakin, F. G. (1992). Electroantennogram of the American cockroach: effect of oxygen and electrical model. J. Comp. Physiol. A 170, 651-663. doi: 10.1007/bf00199341

Kapitsky, S. V., and Zhukovskaya, M. I. (2001). Sensitivity modulation in sex pheromone reception in male American cockroach Periplaneta americana L.: octopamine modifies sensillar firing response. Sens. Sist. 15, 147-154.

Keil, T. A. (1999). "Morphology and development of the peripheral olfactory organs," in Insect Olfaction, ed. B. S. Hansson (Heidelberg: Springer), 5-47.

Kutsukake, M., Komatsu, A., Yamamoto, D., and Ishiwa-Chigusa, S. (2000). A tyramine receptor gene mutation causes a defective olfactory behavior in Drosophila melanogaster. Gene 245, 31-42. doi: 10.1016/s0378-1119(99)0 0569-7

Lange, A. B. (2009). Tyramine: from octopamine precursor to neuroactive chemical in insects. Gen. Comp. Endocrinol. 162, 18-26. doi: 10.1016/j.ygcen. 2008.05.021

Lange, A. B., Orchard, I., and Barrett, F. M. (1989). Changes in haemolymph serotonin levels associated with feeding in the blood-sucking bug, Rhodnius prolixus. J. Insect Physiol. 35, 393-399. doi: 10.1016/0022-1910(89)90113-3

LeDue, E. E., Mann, K., Koch, E., Chu, B., Dakin, R., and Gordon, M. D. (2016). Starvation-induced depotentiation of bitter taste in Drosophila. Curr. Biol. 26, 2854-2861. doi: 10.1016/j.cub. 2016.08.028

Linn, C. E., Campbell, M. G., and Roelofs, W. L. (1992). Photoperiod cues and the modulatory action of octopamine and 5-hydroxytryptamine on locomotor and pheromone response in male gypsy moths, Lymantria dispar. Arch. Insect Biochem. Physiol. 20, 265-284. doi: 10.1002/arch.940200404

Linn, C. E., and Roelofs, W. L. (1986). Modulatory effects of octopamine and serotonin on male sensitivity and periodicity of response to sex pheromone in the cabbage looper moth, Trichoplusia ni. Arch. Insect Biochem. Physiol. 3, 161-171. doi: 10.1002/arch.940030206

Ma, Z. Y., Guo, X. J., Lei, H., Li, T., Hao, S. G., and Kang, L. (2015). Octopamine and tyramine respectively regulate attractive and repulsive behavior in locust phase changes. Sci. Rep. 5:8036. doi: 10.1038/srep08036

McCall, P. J., and Eaton, G. (2001). Olfactory memory in the mosquito Culex quinquefasciatus. Med. Vet. Entomol. 15, 197-203. doi: 10.1046/j.0269-283x. 2001.00304.x

McMeniman, C. J., Corfas, R. A., Matthews, B. J., Ritchie, S. A., and Vosshall, L. B. (2014). Multimodal integration of carbon dioxide and other sensory cues drives mosquito attraction to humans. Cell 156, 1060-1071. doi: 10.1016/j.cell.2013. 12.044

McQuillan, H. J., Barron, A. B., and Mercer, A. R. (2012). Age-and behaviour-related changes in the expression of biogenic amine receptor genes in the antennae of honey bees (Apis mellifera). J. Comp. Physiol. A Neuroethol. Sens. Neural Behav. Physiol. 198, 753-761. doi: 10.1007/s00359-012 $-0745-\mathrm{y}$

Mechaber, W. L., Capaldo, C. T., and Hildebrand, J. G. (2002). Behavioral responses of adult female tobacco hornworms, Manduca sexta, to hostplant volatiles change with age and mating status. J. Insect Sci. 2:5. doi: 10.1093/ jis/2.1.5

Meola, S. M., and Sittertz-Bhatkar, H. (2002). Neuroendocrine modulation of olfactory sensory neuron signal reception via axo-dendritic synapses in the antennae of the mosquito, Aedes aegypti. J. Mol. Neurosci. 18, 239-245. doi: 10.1385/jmn:18:3:239

Mesce, K. A., DeLorme, A. W., Brelje, T. C., and Klukas, K. A. (2001). Dopamine-synthesizing neurons include the putative $\mathrm{H}$-cell homologue in the moth Manduca sexta. J. Comp. Neurol. 430, 501-517. doi: 10.1002/10969861(20010219)430:4<501::AID-CNE1046>3.0.CO;2-U

Minoli, S., Kauer, I., Colson, V., Party, V., Renou, M., Anderson, P., et al. (2012). Brief exposure to sensory cues elicits stimulus-nonspecific general sensitization in an insect. PLoS One 7:e34141. doi: 10.1371/journal.pone. 0034141

Möbius, P., and Penzlin, H. (1993). Stress-induced release of octopamine in the American cockroach Periplaneta americana L. Acta. Biol. Hung. 44, 45-50.

Nagai, T. (1981). Electroantennogram response gradient on the antenna of the European corn borer, Ostrinia nubilalis. J. Insect Physiol. 27, 889-894. doi: 10.1016/0022-1910(81)90090-1
Nagaya, Y., Kutsukake, M., Chigusa, S. I., and Komatsu, A. (2002). A trace amine, tyramine, functions as a neuromodulator in. Neurosci. Lett. 329, 324-328. doi: 10.1016/s0304-3940(02)00596-7

Newport, G. (1836). On the respiration of insects. Philos. Trans. R. Soc. Lond. 126, 529-566. doi: 10.1098/rstl.1836.0026

Nishimura, A., Ishida, Y., Takahashi, A., Okamoto, H., Sakabe, M., Itoh, M., et al. (2012). Starvation-induced elevation of taste responsiveness and expression of a sugar taste receptor gene in Drosophila melanogaster. J. Neurogenet. 26, 206-215. doi: 10.3109/01677063.2012.694931

Ohta, H., and Ozoe, Y. (2014). Molecular signalling, pharmacology and physiology of octopamine and tyramine receptors as potential insect pest control target. Adv. Insect. Physiol. 46, 73-166. doi: 10.1016/b978-0-12-417010-0. 00002-1

Ohta, H., Utsumi, T., and Ozoe, Y. (2003). B96Bom encodes a Bombyx mori tyramine receptor negatively coupled to adenylate cyclase. Insect Mol. Biol. 12, 217-223. doi: 10.1046/j.1365-2583.2003.00404.X

Ohta, H., Utsumi, T., and Ozoe, Y. (2004). Amino acid residues involved in interaction with tyramine in the Bombyx mori tyramine receptor. Insect Mol. Biol. 13, 531-538. doi: 10.1111/j.0962-1075. 2004.00511.x

Oppelt, A., and Heinze, J. (2009). Mating is associated with immediate changes of the hydrocarbon profile of Leptothorax gredleri ant queens. J. Insect Physiol. 55, 624-628. doi: 10.1016/j.jinsphys.2009.03.010

Orchard, I., Gole, J. W. D., and Downer, R. G. H. (1983). Pharmacology of aminergic receptors mediating an elevation in cyclic AMP and release of hormone from locust neurosecretory cells. Brain Res. 288, 349-353. doi: 10.1016/0006-8993(83)90116-6

Pass, G. (1985). Gross and fine structure of the antennal circulatory organ in cockroaches (Blattodea, Insecta). J. Morphol. 185, 255-268. doi: 10.1002/jmor. 1051850210

Pass, G. (2000). Accessory pulsatile organs: evolutionary innovations in insects. Annu. Rev. Entomol. 45, 495-518. doi: 10.1146/annurev.ento.45.1.495

Pass, G., Gereben-Krenn, B. A., Merl, M., Plant, J., Szucsich, N. U., and Tögel, M. (2006). Phylogenetic relationships of the orders of Hexapoda: contributions from the circulatory organs for a morphological data matrix. Arthropod Syst. Phylogeny 64, 165-203.

Pass, G., Sperk, G., Agricola, H., Baumann, E., and Penzlin, H. (1988). Octopamine in a neurohemal area within the antennal heart of the American cockroach. J. Exp. Biol. 135, 495-498.

Pawlowa, M. (1895). Uber ampullenartige Blutcirkulationsorgane im Kopfe verschiedener Orthopteren. Zool. Anz. 18, 7-13.

Pitts, R. J., Rinker, D. C., Jones, P. L., Rokas, A., and Zwiebel, L. J. (2011). Transcriptome profiling of chemosensory appendages in the malaria vector Anopheles gambiae reveals tissue-and sex-specific signatures of odor coding. BMC Genomics 12:271. doi: 10.1186/1471-2164-12-271

Pophof, B. (2000). Octopamine modulates the sensitivity of silkmoth pheromone receptor neurons. J. Comp. Physiol. A 186, 307-313. doi: $10.1007 / \mathrm{s} 003590050431$

Pophof, B. (2002). Octopamine enhances moth olfactory responses to pheromones, but not those to general odorants. J. Comp. Physiol. A Neuroethol. Sens. Neural Behav. Physiol. 188, 659-662. doi: 10.1007/s00359-002-0343-5

Reim, T., Balfanz, S., Baumann, A., Blenau, W., Thamm, M., and Scheiner, R. (2017). AmTAR2: functional characterization of a honeybee tyramine receptor stimulating adenylyl cyclase activity. Insect Biochem. Mol. Biol. 80, 91-100. doi: $10.1016 /$ j.ibmb.2016.12.004

Riffell, J. A., and Hildebrand, J. G. (2016). "Adaptive processing in the insect olfactory system," in The Ecology of Animal Senses, eds G. von der Emde and E. Warrant (New York, NY: Springer International Publishing), 3-24.

Rillich, J., and Stevenson, P. A. (2015). Releasing stimuli and aggression in crickets: octopamine promotes escalation and maintenance but not initiation. Front. Behav. Neurosci. 9:95. doi: 10.3389/fnbeh.2015.00095

Roeder, T. (2005). Tyramine and octopamine: ruling behavior and metabolism. Annu. Rev. Entomol. 50, 447-477. doi: 10.1146/annurev.ento.50.071803.130404

Roeder, T., Seifert, M., Kähler, C., and Gewecke, M. (2003). Tyramine and octopamine: antagonistic modulators of behavior and metabolism. Arch. Insect Biochem. Physiol. 54, 1-13. doi: 10.1002/arch.10102

Roelofs, W. L. (1995). Chemistry of sex attraction. Proc. Natl. Acad. Sci. U S A 92, 44-49. doi: 10.1073/pnas.92.1.44 
Saifullah, A. S. M., and Page, T. L. (2009). Circadian regulation of olfactory receptor neurons in the cockroach antenna. J. Biol. Rhythms 24, 144-152. doi: $10.1177 / 0748730408331166$

Salecker, I., and Distler, P. (1990). Serotonin-immunoreactive neurons in the antennal lobes of the American cockroach Periplaneta americana: light- and electron-microscopic observations. Histochemistry 94, 463-473. doi: $10.1007 / \mathrm{bf} 00272608$

Saleh, N., and Chittka, L. (2006). The importance of experience in the interpretation of conspecific chemical signals. Behav. Ecol. Sociobiol. 61, 215-220. doi: 10.1007/s00265-006-0252-7

Schaller, D. (1978). Antennal sensory system of Periplaneta americana L. Distribution and frequency of morphologic types of sensilla and their sex-specific changes during postembryonic development. Cell Tissue Res. 191, 121-139.

Schendzielorz, T., Peters, W., Boekhoff, I., and Stengl, M. (2012). Time of day changes in cyclic nucleotides are modified via octopamine and pheromone in antennae of the Madeira cockroach. J. Biol. Rhythms 27, 388-397. doi: $10.1177 / 0748730412456265$

Siju, K. P., Hansson, B. S., and Ignell, R. (2008). Immunocytochemical localization of serotonin in the central and peripheral chemosensory system of mosquitoes. Arthropod Struct. Dev. 37, 248-259. doi: 10.1016/j.asd.2007. 12.001

Solari, P., Stoffolano, J. G. Jr., De Rose, F., Barbarossa, I. T., and Liscia, A. (2015). The chemosensitivity of labellar sugar receptor in female Phormia regina is paralleled with ovary maturation: effects of serotonin. J. Insect Physiol. 82, 38-45. doi: 10.1016/j.jinsphys.2015.08.007

Stengl, M. (2010). Pheromone transduction in moths. Front. Cell. Neurosci. 4:133. doi: $10.3389 /$ fncel.2010.00133

Stengl, M., and Funk, N. W. (2013). The role of the coreceptor Orco in insect olfactory transduction. J. Comp. Physiol. A Neuroethol. Sens. Neural Behav. Physiol. 199, 897-909. doi: 10.1007/s00359-013-0837-3

Stevenson, P. A., and Rillich, J. (2016). Controlling the decision to fight or flee: the roles of biogenic amines and nitric oxide in the cricket. Curr. Zool. 62, 265-275. doi: $10.1093 /$ cz/zow028

Takasu, K., and Lewis, W. J. (1996). The role of learning in adult food location by the larval parasitoid, Microplitis croceipes (Hymenoptera: Braconidae). J. Insect Behav. 9, 265-281. doi: 10.1007/bf02213870

Thurm, U., and Küppers, J. (1980). "Epithelial physiology of insect sensilla," in Insect Biology in the Future, eds M. Locke and D. S. Smith (New York, NY: Academic Press), 735-763.

Vander Meer, R. K., Preston, C. A., and Hefetz, A. (2008). Queen regulates biogenic amine level and nestmate recognition in workers of the fire ant, Solenopsis invicta. Naturwissenschaften 95, 1155-1158. doi: 10.1007/s00114008-0432-6

Vergoz, V. H., McQuillan, J., Geddes, L. H., Pullar, K., Nicholson, B. J., Paulin, M. G., et al. (2009). Peripheral modulation of worker bee responses to queen mandibular pheromone. Proc. Natl. Acad. Sci. U S A 106, 20930-20935. doi: 10.1073/pnas.0907563106
Vleugels, R., Verlinden, H., and Broeck, J. V. (2015). Serotonin, serotonin receptors and their actions in insects. Neurotransmitter 2:e314. doi: $10.14800 /$ nt.314

von Nickisch-Rosenegk, E., Krieger, J., Kubick, S., Laage, R., Strobel, J., Strotmann, J., et al. (1996). Cloning of biogenic octopamine receptors from moths (Bombyx mory and Heliothis virescens). Insect Biochem. Mol. Biol. 26, 817-827. doi: 10.1016/s0965-1748(96)00031-8

Watanabe, H., Shimohigashi, M., and Yokohari, F. (2014). Serotoninimmunoreactive sensory neurons in the antenna of the cockroach Periplaneta americana. J. Comp. Neurol. 522, 414-434. doi: 10.1002/cne.23419

Weidenmüller, A., Mayr, C., Kleineidam, C. J., and Roces, F. (2009). Preimaginal and adult experience modulates the thermal response behavior of ants. Curr. Biol. 19, 1897-1902. doi: 10.1016/j.cub. 2009.08.059

Westhus, C., Kleineidam, C. J., Roces, F., and Weidenmüller, A. (2013). Behavioural plasticity in the fanning response of bumblebee workers: impact of experience and rate of temperature change. Anim. Behav. 85, 27-34. doi: 10.1016/j.anbehav.2012.10.003

White, P. R. (1991). The electroantennogram response: effects of varying sensillum numbers and recording electrode position in a clubbed antenna. J. Insect Physiol. 37, 145-152. doi: 10.1016/0022-1910(91)90100-e

Yadav, M. (2003). Physiology of Insects. New Delhi: Discovery Publishing House.

Yang, Z., Bengtsson, M., and Witzgall, P. (2004). Host plant volatiles synergize response to sex pheromone in codling moth, Cydia pomonella. J. Chem. Ecol. 30, 619-629. doi: 10.1023/b:joec.0000018633.94002.af

Zhao, X. C., Pfuhl, G., Surlykke, A., Tro, J., and Berg, B. G. (2013). A multisensory centrifugal neuron in the olfactory pathway of heliothine moths. J. Comp. Neurol. 521, 152-168. doi: 10.1002/cne.23166

Zhukovskaya, M. I. (2008). Selective regulation of sensitivity to odours of different behavioural significance in American cockroach, Periplaneta americana L. Physiol. Entomol. 33, 162-166.doi: 10.1111/j.1365-3032.2008.00615.x

Zhukovskaya, M. I. (2012). Modulation by octopamine of olfactory responses to nonpheromone odorants in the cockroach, Periplaneta americana L. Chem. Senses 37, 421-429. doi: 10.1093/chemse/bjr121

Zhukovskaya, M. I., and Kapitsky, S. V. (2006). Activity modulation in cockroach sensillum: the role of octopamine. J. Insect Physiol. 52, 76-86. doi: 10.1016/j. jinsphys.2005.09.005

Conflict of Interest Statement: The authors declare that the research was conducted in the absence of any commercial or financial relationships that could be construed as a potential conflict of interest.

Copyright $\odot 2017$ Zhukovskaya and Polyanovsky. This is an open-access article distributed under the terms of the Creative Commons Attribution License (CC BY). The use, distribution or reproduction in other forums is permitted, provided the original author(s) or licensor are credited and that the original publication in this journal is cited, in accordance with accepted academic practice. No use, distribution or reproduction is permitted which does not comply with these terms. 